\title{
Trabalho e Saúde Coletiva: o ponto de vista da atividade e das relações de gênero
}

\author{
Work and collective health: the point of view \\ of activity and gender relations
}

Jussara Brito 1

1 Cen tro de Estudos da Saúde do Trabalhador e Ecologia Humana, Escola Nacional de Saúde Pública Sergio Arouca, Fiocruz. Av. Leopol do Bulhões 1480, Manguinhos, 21041-210,

Rio de Jan eiro RJ.

jussarabr@uol.com.br
Abstract Insofar as work is a fundamental activity in life, we try to show the importance of gaining a bet ter understanding of its dimensions for incorporation into analyses of the set of collective health problems. This is why we have adopted approaches that explore the concept of the activity of work, to gether with studies of gender relations, bearing in mind that in both cases the aim is to underline the different dimensions of work. Using the activity of work concept, we get closer to the non-standardizable, changeable and variable nature of life and work situations. We use the concept of health in Canguilhem's work, which draws attention to the active relationship between the individual and his environment (of work), with a view to outlining a debate on the possibility of cre a ting health norms. The materials dealing with gender-based division of laborbasic material of gen der rel a tions - co m bine with the issues raised by the concept of the activity of work, which also provide elements to a better perception of the health/work relationship. At the interface of these two points of view (work as activity and as the embodiment of gender relations) we come face to face with the importance of the experience of workers in the generation of knowled ge concerning health and the need for multiple forms of intervention.

Key words Activity of work, Gender relations, Worker's health
Resumo Na medida em que o trabalho é uma atividade fundamental da vida, procuramos mostrar a importância de melhor compreender suas dimensões para incorporá-las nas análises do conjunto de probl emas de saúde coletiva. Lançamos mão de abordagens que vêm explorando o concei to de atividade de trabalho, bem como dos estudos das relações de gênero, tendo em vista que nos dois casos busca-se dar visibilidade às diferen tes dimensões do trabalho. Através do concei to de atividade de trabalho nos aproximamos do cará ter não padronizável, mu tável e variá vel da vida e das situações de trabalho. A partir da concepção de saúde presente na obra de Canguilhem, que chama a atenção para a relação ativa en tre o indivíduo e seu meio (de trabalho), esboçamos um debate sobre as possibilidades de criação de no rmas de saúde. Os materiais que tratam da divisão sexual do trabalho - base material das relações de gênero - se somam às questões apontadas pelo conceito de atividade de trabalho, contribuindo também para uma melhor percepção da relação saúde-trabalho. Na interface desses dois pontos de vista (tra balho como atividade e como materialidade das relações de gênero) ressaltamos a importância da experiência dos/as trabalhadores/as na produção de saberes sobre a saúde, assim como a necessidade de múltiplas formas de intervenção.

Palavras-ch ave Atividade de trabalho, Relações de gênero, Saúde do trabalhador 


\section{Introdução}

O obj etivo de s te arti go é discutir algumas que stões rela tivas ao mundo do trabalho, ten do como perspectiva contribuir com o desenvolvimen to da área de Sa ú deCol etiva. Nessa área do conhecimen to e intervenção en contramos o campo denominado Saúde do Trabalhador em cuja con s ti tuição o Brasil teve um papel decisivo -, que tem se ocupado desta questão, fundamental para a vida. Nesse sentido, este campo a nosso ver repres enta um avanço em comparação a diferen tes abordagens con temporâneas sobre a relação trabalho-saúde, muitas vezes desvinculadas das preocupações da saúde pública. Entretanto, não se poderia deixar de assinalar que apesar de sua ri queza e originalidade (dificilmen te en contramos propostas similares em outros países, mesmo na Am érica Latina), o campo da Saú de do Trabalhador $\mathrm{p}$ a rece não ter sido ainda plenamente absorvido da forma mais pertinente e em toda sua magnitude pela área da saúde que lhe comporta. Além de observa rmos uma certa insistência, em alguns espaços (sejam eles acadêmicos ou não) em perseverar na denominação "saúde ocupacional" parase referir aos estudos e ações que envolvem o trabalho, percebemos que o patrimônio con s truído no campo da Saúde do Trabalhador permanece sendo tratado como específico, não sendo con si derado, portanto, de in teresse geral da Saú de Coletiva. Dois fatores, em especial, podem ajudar a compreen der esse fato. Primeiro, a necessidade de manter acesa a reflexão sobre o campo em foco, tra zendo novos aportes e, assim, ren ovando e divulgando as idéias que lhe são subjacentes. Em segundo lugar, o estatuto dado ao tema do trabalho no s eio da Saúde Coletiva. Sobre esse segundo ponto é importante sinalizar que uma contribuição do campo da Saúde do Trabalhador poderia ser reafirmar a necessidade de se integrar o trabalho nas análises dos condicionantes da sa údeda população, em geral. Em bora esta não seja uma proposta nova, pois estava presente nos primórdios da con sti tuição do campo, parece haver o entendimen to de que apenas um certo número de problemas, bem delimitados, se associam ao trabalho e outros não. Em outras palavras, talvez se entenda que apenas as s i tuações em que o trabalho está cl a ra e diret amen te associ ado às formas de adoecimento devem ser objeto de uma análise do campo. Ou ainda, que o processo de trabalho só seria de in teresse para a Saúde Col etiva quando a vin- culação com os processos patológi cos forem mu i to níti dos (diretamente ob s erváveis, obj etiváveis, mensuráveis), aproximando-se ou confundindo-se com o en foque que, em nosso entendimento, deve ser su perado (Saú de Ocupacional). Cabe lembrar que o campo da Saúde do Trabalhador se originou na luta dos traba$1 \mathrm{~h}$ adores pelo direi to à saúde, no bojo da Reforma Sanitária e com inspiração no Movimen to Operário Italiano (MOI), propon do o proce sso de trabalho como categoria fundamental para análise das relações en tre o trabalho e a saúde. Assim, visa estudar e intervir nessas relações a partir do processo de trabalho, mas incorpora n do a experiência/subj etividade do trabalhador nas pe s quisas e ações, apon ta ndopara uma noção de saúde como luta contínua, uma conquista perman en te, em meio às forças políticas. Para nós (Bri to, 2004), es te campo é acima de tudo uma pers pectiva diferenciada de estudo, a tenção e intervenção sobre os problemas relativos à saúde dos trabalhadores; uma forma de ver, entender e desenvolver ações práticas, a partir de olhares de diferen tes especialistas e olhares dos trabalhadores e das trabalhadoras, com vistas a garantir a ótica de gênero.

$\mathrm{Na}$ medida em que o trabalho representa uma dimensão fundamental da vida, constituise então em um elemento que sem pre atravessa a probl em á tica da saúde. Como afirma Dejours (1995), o trabalho nunca é neutro em relação à saúde: ou é operador de saúde ou é patogênico. Nesta abordagem (Dejours, 1986), a questão não é disjuntiva - "trabalho ou não trabalho?" - e sim: qual trabalho? Nesse sen tido, é imprescindível uma discussão sobre o próprio con ceito de trabalho que adotamos. Assim, um esforço de mel hor com preen der o que é trabalhar sua importância na vida dos hom ens e das mulheres - poderá con tribuir para a maior e mais rica incorporação das problemáticas pertin entes à Saúde do Trabalhador no âmbi to da Saúde Coletiva. Contamos, para isso, com desenvolvimentos de diferen tes disciplinas que fazem uso do con cei to de atividade, e que enfatizam a complexidade e variabilidade das situações, sua dinâmica e a mobilização dos trabalhadores no próprio processo. Além disso, ao procurar melhor com preender o que é trabalhar, cruzamos com os estudos sobre as "relações sociais de sexo", pois esses além de ampliar a noção de trabalho e de desconstruir outras correlatas - como a de qualificação - apontam que o trabalho está no cen tro dos conflitos entre os grupos sociais femininos e masculinos. 


\section{O que é trabalhar?}

Os sen ti dos atribuídos ao trabalho são diferentes em um mesmo mom en to histórico (na Grécia antiga, não se en con tra um vocábulo designando o trabalho em geral, mas: ergon, scholè, techné, ponos, práxis, poièsis) e se modificam com o tempo: se nos séculos 9 e 10 seu sentido predominante (cristão) era de pena/penitência e sofrimen to (tripalium) e no século 13 de exercício de um ofício, no século 18 essa noção passa a ser correl acionada às atividades produtivas (em uma deriva produtivista) que se desenvolvem sob as relações sociais dominantes (capitalistas) e assim glorificadas. Além disso, em função da diversidade de práticas existentes, o que é con si derado trabalho varia de uma socied ade a outra, o que implica a inclusão ou exclusão de certas atividades desta noção, segundo os critérios que lhe defin em(Terssac \& Maggi, 2004).

Entretanto, a noção moderna de trabalho está fortemente vinculada ao conceito engendrado pela economia política. Esta envolve uma visão antropológica, na medida em que o trabalho é caracterizado como um ato que se passa en tre o hom em e a natureza, e coloca em rel evo uma segunda característica, que diz respeito ao fato de que as trocas entre homem e natureza ocorrem sob condições sociais determinadas. Con forme Hirata \& Za rifian (2000), essa segunda definição possibili tou avançar na con cei tualização de trabalho assalari ado, inaugu ra n do a idéia de trabalho como ativid ade social mensurável e passível de ser objetivada ( como trabalho abstrato). Nos anos 70 do século 20, essa noção foi parcialmen te criticada pelo fato de partir de um modelo assex u ado do trabalho, em que o masculino é apresentado como universal e as relações de gênero não são contempladas, além de se limitar à esfera da produção e de não incluir adequadamente as formas de trabalho diferentes da assalariada. Neste mesmo período os er gon omistas da atividade mostra ram também que a visão genérica de trabalho não correspon de ao que de fato se efetiva, propondo os conceitos de trabalho pres crito (tarefa) e trabalho real (atividade re alizada). Já nos anos 90, diante de con ju n tu rade crise econômica, recessão e diferen tes formas de desemprego - tecnológico, estrutural e de longa duração -, assistimos a uma atualização do debate sobre o trabalho, emergindo, entre o utras questões, a enunciação do "fim do trabalho" (Rifkin, 1995). Em meio a este debate, alguns autores reafirmaram a centralidade do trabalho, evidenciando que o propalado "fim do trabalho" seria na verd ade o fim da definição de trabalho instaurada pela "econ omia política", isto é, o trabalho assalariado (ou a "forma salaria to"). Como indicam Hirata \& Zarifian (2000), as análises que separam o trabalho de outras esferas da vida (criação, ação política) acabam hiera rquizando as atividades humanas, in feri orizando aqu ela que é den ominada de trabalho, que fica cristalizadocomo lugar de obj etivação e con trole, s em possibilidade de s er criativo, su bvertido e transformado. Com o tayl orismo essa idéia ganhou de fato uma gra nde adesão, produzindo até mesmo a crença de que o trabalho é totalmente determinado externamen te pela forma que é organizado pela "gerência científica" (ou melh or, pelos re s ponsáveis pela prescrição). Outra crença então gerada é que no chamado "trabalho manual" os in divíduos agi riam de forma inteiram en tesimplificada, mecânica, s em mobilizar-se psicologicamente (cogni tiva, a fetiva m en te) e sem criatividade alguma (Wisner, 1994). Com o taylorismo e o fordismo proc $u$ rou-se estabel ecer um acordo em torno do aumento da produtividade, da redução do desgaste e dos ganhos salariais. Tal acordo estava pretensamen te baseado no respei to à prescrição, à tarefa, mas paradoxal e não formalmente exigia dos operadores uma mobilização capaz de detectar e interpretar os limites da prescrição, a presença de variabilidades e chegar a modos operatórios reguladores. Ou seja, uma inventividade que se configurava em ren ormalizações, em moleculares ações inven tivas, a um custo el evado para os trabalhadores no plano psicoss omático(Doray, 1981; Dejours, 1987). Com a crise do taylorismo e do fordismo vêm sen do experimentadas pelo capital novas formas de organização do trabalho, em que se exigiria maior implicação dos trabalhadores, mas ainda assim a idéia de que o trabalho é totalmen te defi in i do previamente por regras e instruções tem se mantido predominante - apesar das diversas análises que demonstraram ser o trabalho de fato uma atividade enigmática e complexa. Estamos nos referindo aqui ao importante legado deixado seja pelo que se conquistou a partir da experiência acumulada com o Movimen to Operário Italiano de luta pela saúde (anos 60), seja pelas descobertas de um conjun to de disciplinas/abordagens que foram se constituindo na França e na Bélgica, a partir desse mesmo período como a que se deu pela ergonomia da 
atividade, em seguida explorada pela psicodinâmica do trabalho, pela ergologia e pela dínica da atividade.

O movimento italiano trouxe à tona a questão de que o processo de contínua aprendizagem, que se desenvo lve por via da ex periência, por sua transmissão e pela reflexão coletiva nela originada é en con trado mesmo nos trabalhos de mais simples execução. Nos seminários reali$\mathrm{z}$ ados com del egados sindicais ou mem bros de conselhos de fábrica, os trabalhadores se referiam a seus trabalhos como algo estimulante e dinamizador de sua inteligência, habilidade psicom o triz e capacidade de criação (Oddone, Re \& Brianti, [1977] 1981). Para Clot (1981), os trabalhadores desenvolvem uma experiência "informal", pois mesmo no taylorismo outro tipo de saber circula nos espaços produtivos.

Uma contribuição decisiva da ergonomia da atividade (denominação que qualifica um pon to de vista particular sobre o trabalho) aos estudos sobre o trabalho foi detectar que o trabalho não se resume à prescrição, ou seja, que há, de um lado, o trabalho teórico/prescrito (definido pelas or ganizações através da definição de métodos e procedimentos, o que foi posteriormen te design ado pela er gon omia como a tarefa) e, de outro, o trabalho real (que se con s ti tui nas situações concretas, com suas variabilidades, posteriormente designado atividade realizada). De fato, a des coberta da existência de uma defas agem, um hiato entre aqu ilo que se proj eta previam en te como trabalho e o que ele real $m$ en te repre s enta e envo lve é mu ito valiosa, na medida em que permite dar um n ovo sen ti do para essa atividade humana, coloca ndoem evidência as dificuldades e desafios enfrentados por aqueles que a des envolvem. Essa descoberta nos instrumentaliza no combate a todo tipo de argumentação dirigida a de s qualificar o trabalho, qua n do este não exi ge uma capacitação profissional formalizada, a negar a sua complexidade. Essa descoberta alerta para o risco de uma visão empobrecida (e empobrecedora) do trabalho, prejudicando a análise dos elementos que podem ser (des) favor á veis à saúde. Em outras palavras, uma análise baseada exclu sivamente no trabalho prescrito/teóri co rem ete a uma avaliação equivoc ada dos condicionantes da saúde, pois não traduz o real do trabalho e os modos operatórios reguladores en gen drados e implem en tados pelos trabalhadores no curso da ação, que implica modificações das pró prias situações. Por esse motivo, esse tipo de análise, que poderíamos ca racterizar de "abstrata" (baseada no trabalho abstra to e que não retrata o trabalho concreto, aí incluído o que se den omina o real do trabalho), não permite ir muito mais além do que proceder à iden tificação dos clássicos "fa tores de risco" (muitas vezes sem considerá-los sequer em sua siner gia, conforme ressaltado pelo MOI). Com essa de s coberta o trabalho passa a ser compreendido, por essa linha da ergonomia, a través de suas dimensões - a tarefa e a atividade, poden do então ser assim definido: $O$ trabalho é uma atividade finalizada, realizada de uma maneira individual ou coletiva em determinado período de tempo, por um determinado homem ou mulher, situada em um contexto particular que fixa as limitações imediatas da situação. Esta atividade não é neutra, compromete e transforma, até mesmo aquele que a realiza (Teiger, 1993, tradução nossa).

O foco de estu do e ação consistirá, a partir dessa descoberta, na atividade de trabalho, con ceito também privilegiado e desenvolvi do na abordagem ergológica (con forme veremos adiante). Antes disso vamos destacar de que forma a psicodinâmica do trabalho aborda o "real do trabalho". Em prim ei rolugar, Dejours (2004) evi dencia através das pesquisas realizadas por essa disciplina que existe o que se pode chamar de uma organização prescrita do trabalho e uma organização real do trabalho. Em o utras palavras, revela-se aí que o trabalho é en gendrado em con $\mathrm{f}$ ron to (e negociação) com o real - caracteri zado como aquilo sobre o que não se tem con trole (rem eten do à experiência do revés) quando se segue apenas os procedimen tos previstos ou os conhecimen tos já existen tes. Nessa linha, o trabalho é definidocomo a atividade coordenada de senvolvida por hom ens e mulh eres para conseguir o que na produção não pode ser obti do pela estrita execução prescrita do trabalho (Davezies, 1993). Logo, o trabalho é sempre humano por essência ou definição (Davezies, 1993; Dejours, 1995).

As questões trazidas pela ergologia - abordagem inspirada em diversas influências, como a ergonomia, o Movimen to Operário de Luta pela Sa ú de (MOI) e a obra de Georges Canguilh em - vão reforçar as proposições já apresentadas. Em primei ro lugar, Schwartz (2000) é bastanteassertivo qua ndo enuncia que não seria possível viver sob total heterodeterminação. Por esse motivo, os homens e as mulheres fazem um uso de si por si, além de um uso de si pelo outro. Dito de outro modo, para viver e trabalhar, buscam recriar o meio, produzindo 
novas normas (Canguilhem, [1947] 2001). O ângulo a partir do qual Schwartz observa o trabalho é aqu ele que ten de a ser negado-ign orado pelas organizações. É o ângulo da vida, do trabalho vivo, buscan do iden tificar os "possívei s", presentes nas ativid ades. Encon trar a vida presente no processo de trabalho nos parece fundamental quando preten demos construir alternativas - em parceria com os protagonistas da atividade - que favoreçam a saúde dos gru pos envolvidos. Eviden temen te isso pres supõe um tipo de saber, uma inteligência da prática, que não pode deixar de ser considerada como aliás já ch a mavam atenção Ivar Oddone e seus parcei ros na década de 1970 (Oddone; Re \& Brianti. [1977] 1981).

O interesse em adotarmos o "pon to de vista da atividade" está na possibilidade de explorarmos outros caminhos para o necessá rio desenvolvimento do campo da Saúde do Trabalhador, con tribuin do com o avanço de um de seus princípios - a interdisciplinaridade - na medida em que este ponto de vista exige o cruza$m$ en to de en foques. Colaborando também para potencializar outra "questão-ch ave", a integração da experiência dos trabalhadores no processo de produção de conhecimen to (Laurell \& Noriega, 1989), cuja sinergia - fecundo cruzamen to de enfoques - exige uma postura de humild ade epistemológica e a disposição para retrabalhar os conceitos em diálogo crítico com os saberes da experiência (também a serem retrabalhados), con forme propõe a ergologia (2000). Nesse sen ti do, coloca-se em paut a as repres entações científicas sobre a realidade, uma vez que, conforme lembra Czeresnia (2003), deve-se considerar um aspecto fundamental da construção da racionalidade científica: os limites dos conceitos de saúde e de doença em referência à experiência con c reta da saúde e do adoecer. Limites que parecem ser ainda mais prof un dos qu a n do a questão em foco é a relação saúde/trabalho.

O con cei to de ativid ade perm $i$ te com preender o trabalho como um lugar permanente de micro-escolhas - de deb a te de normas e valores (Schwartz, 2000) -, pois o sujei to, nesta situação, é colocado diante de diferen tes racionalidades: racionalidade/n orma imposta pela hierarquia e racionalidade/norma do próprio coletivo de trabalhadores (seu patrimônio, suas de scobertas cotidianas e valores - econômico, social, político, de solidari ed ade, saúde etc.).

É import a n te ainda sinalizar que o con cei to de atividade está no centro de abord a gens que buscam efetiva $m$ en te articular pe s quisa e intervenção sobre o processo de trabalho. E, por outro lado, em meio ao deb a te sobre o fim do trabalho, ele é até mesmo apontado como mais adequado do que as noções de emprego e de trabalho (em seu senti do genéri co, cf. Hirata, 2002). Não há, en tret a n to, uma definição única de atividade de trabalho. Para os er gonomistas da atividade ela pode ser definida como uma resposta a constrangimentos impostos exteriormen te ao trabalhador, sen do esta simultaneamen te suscetível de os transformar. Guérin et al. (2001) afirmam que ao falarem de situ ação de trabalho não se referem som en te à tarefa e ao seu ambien te físico, mas também à dim ensão histórica em que a atividade se proce ssa. Buscando avançar nesta mesma direção, a partir da Clínica da Ativid ade, Clot (2001) enten de que o significado da atividade se encontra no movimento de reconcepção da tarefa, para assim atribuir outras finalidades à ação além daqu elas previstas pelos or ganizadores .

Enfim, afirmamos a importância de incorporar o pon to de vista da ativid ade porque enten demos, como Schwartz (2000), que o trabalho é lugar de rec riação daquilo que foi formulado ex tern a men te e antes mesmo do início do processo. $\mathrm{O}$ con cei to de ativid ade se refere a essa recriação remetendo ao caráter não totalmen te pad ronizável da vida e do trabalho. Assim, a própria negação (ou ignorância) de que existe uma defasagem entre tarefa e atividade pode ser danosa à saúde, pois as estratégias desenvolvidas na ação representam exigências físicas e psíquicas intensas. S chwartz (1988) resume em poucas palavras esta idéia: identificar o trabalho ao trabalho prescrito seria povoar a esfera da produção material de trabalhadores doentes.

Temos aqui, como dissemos, uma forte aproximação com a perspectiva de saúde pres en te em Canguilhem, p a ra qu em a instabilidade é uma característica das situações de vida e trabalho. Em suas palavras o meio é sem pre infiel, sendo a saúde uma margem de tolerância às infidelidades do meio e a capacid ade de criar novas normas (Canguilhem, 1990). Com base no próprio Canguilhem, Le Blanc (2002) salienta que não ocorre exclusivamente uma adaptação do ser humano aos imperativos do trabalho, pois neste caso a atividade subjetiva corresponderia apenas a uma interiorização das normas exteriores. O ser humano, como suj ei to cri ador de normas, vive seu trabalho também a partir de suas preocupações, na medida 
em que a realização de uma tarefa passa pela invenção de um uso de si (Schwartz, 2000). O autor prossegue dizendo que a vida no trabalho não se re sume a imposições, mas que ex prime outras polaridades (afetiva, in telectual, cultural), cujo mau uso no trabalho pode comprom eter a saúde. Logo, para ele, reduzir o trabalho à manutenção das normas é ver a vida humana sob o ângulo da doença - que é o primado do idênti co e justamente a impossibili$\mathrm{d}$ ade de fazer aparecer o novo - mais do que da saúde - que é criação do novo e simultaneamente recusa do idêntico. O caráter patológico desta redução engendra uma separação entre vida e trabalho, em que o trabalho sem pre terá um valor negativo. A reconciliação do trabalho e da vida é obtida pela possibilidade de criação, pelos trabalhadores, de "micro-normas" no meio de trabalho. Com base nisso, nos perguntamos: não caberia ao campo da Saúde do Trab alh adorprivilegiar estudos e intervenções que possibilitem a ampliação da capacidade dos trabalhadores de criarem novas normas (inclusive de saúde) relacionadas a cada situação, com suas singularidades?

Para melh or com preen der essa reflexão (Le Blanc, 2002), cabe lembrar que Canguilhem enten de a saúde como polarid ade dinâmica entre o indiví duo e o meio: O co rpo que vive é esse existente singular, cuja saúde exprime o tipo de poderes que o constituem na medida em que ele deve viver sob imposição de tarefas, em relação de exposição a um ambiente onde ele, inicialmente, não escolhe. O co rpo humano que vive é o co nj u n to dospod eres de umexi sten te que tem capacidade de avaliar e de representar para ele mesmo esses poderes, seu exercício e seus limites.

Com isso chama atenção que as imposições do meio, das tarefas, estarão de alguma forma sempre presentes, porém a vida do corpo em ação (no trabalho, por exemplo) é expressa pelo seu poder de en frentar essas imposições, a partir de avaliações de seu próprio poder. Entendemos que se trata aqui de um poder também coletivo: o que mudar e como mudar esse ambi en te nocivo que en contramos? Para melhor enten dermos essas idéias, podemos prosseguir com a seguinte reflexão (Canguilh em 1990): "o corpo é simultaneamente um dado e um produto". O corpo é um dado na medida em que ele é um genótipo, efei to necessário e singular dos compon en tes de um patrimônio genético. Nesse caso, códigos genéticos que podem ou não determinar efei tos patológicos, con forme o $\mathrm{m}$ eio em que se vive. É um produto, na medida em que sua atividade de inserção em um meio característico, seu modo de vida escolhido ou imposto, esporte ou trabalho, contribui para modelar seu fenótipo, isto é pa ra modificar sua estrutu ra morfológica, levando a singularizar suas capacidades (idem). A saúde, como estado do corpo dado, está ligada às margens de segurança orgânica. A má saúde é a limitação do poder de tolerância e de compensação das agressões ambientais. A saúde, como expressão do corpo produto, é uma segurança vivida no sen ti do duplo de seg u rança con tra o ri s co e da audácia para corrê-lo. É o sen ti m en tode uma capacid ade de ultrapassar capacidades iniciais. Para Caponi (2003), devemos considerar a complexidade desta distinção aparen tem en te trivial, pois tudo parece indicar que é mais simples normalizar condutas do que tran sformar condições perversas de existência. No que tange à Saúde do Trabalhador isso remete à com preensão de como o $m$ eio de trabalho intera ge com o corpo, dandose maior ou menor ênfase à sua dupla condição. Em outras palavras, o quanto se apreende de forma equilibrada essa dupla relação com o meio. Os estudos, bem como as ações, estão orientadas mais no sentido de intervir no poder do corpo de compensar as agressões ambientais (a través da assistência e de regula mentação dos danos à saúde) ou no poder de mudar as condições ambi entais inicialmen te dadas (através da redução da exposição a riscos ou, como apontamos anteri ormente, de intervenções dirigidas à ampliação da capacidade de criação de normas de trabalho com vistas à saúde)?

Essas questões remetem evidentemen te à discussão sobre a con cepção de atividades de prevenção e promoção da saúde ligada ao tra b alho, bem como às con cepções de intervenção. Para Caponi (2003) as intervenções diri gidas à redução de exposições a condições de vida insalu bres são essenciais se com preen dermos que a saúde só pode ser pen sada nesta polaridade dinâmica, vinculada ao mesmo tempo ao indivíduo e ao mei o: É no interior de um meio capaz de garantir uma existência saudável que o indivíduo podeconstituir-se como um sujei to capaz de tol erar as infrações e as infidelidades a que estamos expostos (idem). Essa autora propõe uma discussão sobre estratégias de prevenção e de promoção da saúde baseada na com preensão de Canguilhemde que a saúde implica segurança contra os ri s cos, audácia para corrigi-los epossibili$\mathrm{d}$ ade de su perar nossas capacid ades iniciais. As estratégias de prevenção das doenças poderiam s er con cebidas a partir dessa prim ei ra implica- 
ção da saúde (seg u rança con tra os riscos), privilegiando a minimização da exposição a riscos desnecessários. Por sua vez, as estratégias de promoção da saúde deveriam considerar que a saúde implica algo mais, privil egiando a maximização da capaci d ade dos indivíduos para enf rentar e corrigir aqu eles ris cos ou traições que inevitavelmente fazem parte de nossa história. Entendemos que essas refl exões são bastante coeren tes com o campo da Saú de do Trabalhador e podem de fato con tri buir com s eu avanço teóri co. É coeren te no senti do de que originalmente este campo nasce de uma recusa de modelos de análise que desconsideram a subjetividade/ex periência dos trabalhadores, ou seja, que negam a capacidade que eles têm para detectar o que é noc ivo à saúde no ambi en te de trabalho. É coerente também porque se trata de uma abordagem que preten de tanto atuar na segurança contra os ris cos (intervin dono ambiente e processo de trabalho) qu a n to pre s supõe a necessidade de construção de parcerias en tre profissionais de saúde e trabalhadores (entre outros) para o enfrentamento e correção desses riscos. Para esse enfrentamen to é imprescindível conhecer o en torno, ou seja, detectar o que nel e precisa ser transformado, pois, como a obra de Canguilhem aponta, viver é também con hecer. Como polaridade dinâmica, a vida não é apen a s su bmissão ao meio, mas também instituição de s eu pró prio meio e, portan to é uma forma de conhecimento. Pa rece ser nesse sentido que Ta m bellini (1976), ao teorizar sobre o campo da Sa ú de do Trabalhador, fala em "m odos de andar a vida", referin do-se à capaci d ade das col etividades de res pon der com plasticid ade às condições em que vivem, em correspondência ao que Canguilhemdesigna como modos de ser da vida. É in teressante chamar a atenção aqui que a ativi$\mathrm{d}$ ade de trabalho é sem pre um desafio e que em s eu de senvolvi $m$ en to os trabalhadores precisam s er "audaciosos" ( con forme ex pressão de Canguilhemna obra acima citada) para fazer frente ao que não é dado pela or ganização (prescrita) do trabalho. Essa audácia implica sempre correr riscos, como bem discute Nou roudine (2003). Por isso pensamos ser fundamental buscar uma perspectiva situada das ações de prevenção e promoção da saúde dos trabalhadores, ou seja, que as normas de trabalho e de saúde tenham uma base con creta, os modos opera tó rios utili$\mathrm{z}$ ados pelos trab alh adores e sua ativi d ade de trabalho em sen ti do mais amplo (Clot, 2001).

Por fim, valer dizer que essas questões nos rem etem ao que Schwartz (2000) den omina de desco nfo rto intelectual (e à necessária humildade epistemológica), pois é incômodo/descon fortável reconhecer os limites dos con cei tos científicos diante de uma realidade tão complexa como o trabalho em sua relação com a saúde. É incômodo reconhecer as limitações dos modelos de intervenção que utilizamos, até porque seus efeitos tenderão a ser sempre muito a quém do que é esperado pelos trabalhadores e podem mesmo ser contrários ao que eles desejam (especialmen te se o envolvimen to desses no processo for restrito). Logo, nos parece fundamental uma análise sobre os conceitos que vêm sen do ado tados neste campo da Sa ú deColetiva, visando a um desempenho profissional mais satisfatório e mais próximo daquilo que anseia a população de trabalhadores e trabalhadoras.

\section{Outros olhares sobre o trabalho: con tribuições dos estudos de gênero}

Como já dissemos, ao tentar mel h or compreender o que é trabalhar, ch egamos aos estu dos que tratam das "relações sociais de sexo", que ao problema tiza rema divisão sexual do trabalho, a mpliaram a pró pria noção de trabalho. Da mesma forma que as análises apresentadas acima demon s tra ramser o trabalho uma ativid ade en igmática, esses estudos permitiram o en tendimento de que as relações de gênero atravessam o mundo do trabalho, constituindo-se em mais um compon en te de sua complexidade.

Um el emen to importan te colocado por esses estu dos se refere à necessidade de recusar a oposição universal/particular, na medida em que a idéia de universal reflete apenas um único pon to de vista, n egan do a pluralidade de perspectivas, demandas e necessidades. Por esse motivo, é proposta a produção de "conhecimentos situado s" (Haraw ay, 1988), is to é, inscritos numa rede densa de interações em que se valoriza as singularidades. Esta questão nos permite escla recer que esse é mais um desafio do campo em análise nesse texto: romper com a iden tificação do trabalho masculino como universal. Se de um lado isso nos remete a uma análise mais cuidadosa das singularidades; de outro, nos conduz a colocar o foco sobretudo nas relações sociais (em que classe e sexo social são considerados co-ex ten sivos), tal como defen de Ker goat (2000). Para essa autora, as rel ações sociais de sexo têm uma base material: a divisão sexual do trabalho, con sti tuída por siste- 
mas de hiera rquização e poder. Diversos estudos, es pecialmente os que envo lvem comparações intern acionais, como os realizados por Hirata (2002), mostram o caráter heurístico do con ceito de divisão sexual do trabalho, pois ele permite considerar a multidimensionalidade do trabalho. Permite apreender seus aspectos sociais, econômicos, or ga nizacionais e subj etivos, exigindo a conjugação de diferen tes análises te ó ricas para sua análise. Além disso, como instrumento con ceitual, a divisão sexual do trabalho favorece a visibilização das diferen tes modalidades de atividades e suas articulações, poi s coloca em evidência uma das formas pela qual a sociedade organiza a produção e a reprodução. Para Haicault (1984) deve ser dada ênfase ao trabalho mental neces sá rio para arealização de tarefas superpostas, vinculadas à produção $\mathrm{e}$ à reprodução. Portan to, para a autora a noção de dupla jornada não seria a mais adequada para definir essa imbricação, pois ela na verdade não correspon de a uma adição de tarefas. Propõe uma análise que esteja atenta ao tempo e ao espaço e suas conexões, além do modo como o trabalho profissional recicla as competências exigidas no trabalho doméstico. Nessa mesma direção, é sugerida uma análise que conjugue trabalho remu nerado e não remu n erado, assim como que se considere a "saúde do tempo" (Brito, 1999). Essa proposição se ju s tifica primei ramen te pelo fato de que em muitos casos a remuneração das mulheres (e dos homens) é proveniente de mais de uma atividade profissional e o trabalho não remun erado não se limita ao doméstico. Em segundo lugar, essa proposição busca co locar em evidência a ex tensão do tempo e sua forma de uso como condicionante de saúde/dœnça. Podemos falar ainda da importância de colocar em foco as pressões do tempo, ten do em vista que a alternância trabalho/tempo livre não é ex perimentada por gran de parte das trabalhadoras e que a simultaneidade das ta refas e os ritmos intensos são exigências comuns nas diversas modalidades de trabalho feminino.

O valor heurístico do conceito de divisão sexual do trabalho se revela na possibilidade de detectar suas novas fron teiras, engendradas a partir dos mesmos princípios: a separação (do trabalho das mulheres e dos homens) e a hierarquização (maior valorização do trabalho masculino). Como já mostraram as pesquisas históricas, as mulheres sempre trabalharam: o problema é, portanto, reconhecer o trabalho profissional realizado por esse grupo, ou seja, i den tificar a evo lução das formas de divisão sexual do trabalho. Uma explicação para sua permanência na penu m bra é que em muitos casos o trabalho profissional das mulheres guarda proximidade com o trabalho doméstico, além de muitas vezes ser realizado no espaço privado, caracterizando-se assim pela atomização. O utra explicação é a insistência em tomar as competências requeridas nessas atividades como qualid ades natu rais, man ten do-o na invisibilidade e implicando sua desvalorização. Entret a n to, o trabalho em costura, na agricultura e no comércio, en tre outros, não se con s ti tu em de fato ativid ades novas para as mulheres. São, ao con trário, exemplos de trabalhos precários, a tomizados e invisibilizados que as mulheres de s envolvem há muito tem po, muitas ve zes em troca de rendimentos coletivos ou familiares e que se efetivam em grandes jornadas. Da mesma forma, as atividades ligadas ao cuidado com o corpo (como a en fermagem e assistência social) sempre foram assumidas pelas mulheres, até mesmo sem serem remu n eradas. E ainda há todo um espectro de empregos de escritório.

Como afirma Daune-Ri ch a rd (2003) as atividades de serviço são excluídas de uma representação em termos de tecnicidade e são con s ideradas pertencentes a um universo de trabalho em que são requeridas qualidades ineren tes à natu reza feminina, mascaran do as competências que são aí mobilizadas. Se a divisão sexual do trabalho operário é apoiada no discurso da fragilidade e paciência feminina, a plasticidade das relações sociais de sexo permi te um discurso atual em que a "natu reza feminina" é caracterizada pelo senso prático e pela capacidade de entrar em relação com os outros (Tahon, 2004), exigência dos novos setores produtivos contemporâneos. Cabe ressaltar que a tendência atual de aguçamen to da divers i d ade e heterogen ei dade das situações de trabalho exige maior atenção para atividades não tradicionais e atípicas, muitas delas do chamado setor informal, que vêm inclu s ive aproximando o trabalho feminino do masculino. Para Thébaud-Mony \& Appay (2000), a prec a rização en con tra legitimidade nas formas instituídas de divisão do trabalho social entre homens e as mulheres.

É importante ainda registrar o papel desempenhado pelo trabalho domésti co no Brasil. Con forme Costa (2002), o exame de certos "trabalhos por en comenda", fora das casas, como a lavação de roupas, mostra que, no Brasil, essa e outras atividades se con centram nas casas, ainda hoje, ao contrário de outras expe- 
riências de países capitalistas avançados industrialmente, em que as lavanderias coletivas se propagaram rapidamente. Sinaliza que nem a presença, no merc ado brasileiro, dos aparel hos el etrodomés ticos nos anos 50 (século 20) pode mudar, significativamente, a aplicação do tempo feminino às coisas do lar, ten do em vista as taxas de natalidade e o grande tamanho das proles. A autora acre scenta o fato de que a delegação de cuidados da casa a outras mulheres se dá porque não há outra alternativa - públ ica/coletiva - o que ocorre muitas ve zes através de meios informais de remuneração daquelas que assumem os afazeres domésticos.

Por outro lado, observa-se que as implicações do trabalho "desqualificado" se estendem à família (Ma rcon des et al., 2003), corrobora n do com a tese da centralidade do trabalho. Os estu dos de gênero acabam mostran do que os estereótipos de masculinidade e feminilidade são a propriados pela lógica dominante de divisão s exual do trabalho, gera n do assim uma banalização dos ris cos do trabalho, tan topara as mulheres quanto para os homens (Vogel, 2001). Dessa forma, esses estudos indicam a importância de considerar a divisão sexual do trabalho em toda análise e intervenção acerca da saúde do trabalhador, assim como apontam a necessidade de elaboração de con cei tos relativos às nocividades das situações de trabalho que tenham como referência as experiências das trabalhadoras e trabalhadores (Brito, 1999). Em complemen to a essa proposição, Doyal (1994) sugere que mesmo nas investigações sobre a violência doméstica é preciso levar em conta a d ivisão sexual do trabalho, pois o domicílio deve ser apreendido como um local de trabalho, o que en ten demos como mais uma indicação da capacid ade con tida no campo da Sa ú de do Trabalhador no sentido de interpelar toda a área da Sa ú de Coletiva. Já Ma rcon des e colaboradores (2003) mostraram claramen te que a interação en tre trabalho domésti co e remun erado é um aspecto-chave na compreensão do impacto diferenciado das condições de trabalho sobre a saúde dos homens e das mulheres. Os autores indicaram que se de um lado a adaptação das mulh eres ao trabalho notu rno depen de da ajuda de familiares (pois durante o dia elas também trabalham em casa, ao contrário de seus colegas de fábrica), a expectativa de prover as n ecessidades da família parece constituir uma a tribuição que gera novos sofrimentos para os homens. De fato, na medida em que en tendemos que é necessário uma compreensão am- pliada do que seja saúde, considerando o ser humano nas suas dimensões biológica, psicossocial e histórica (Brito, Athayde \& Neves, 2003), a incorporação da probl emá tica do trabalho em sua amplitude e complexidade (que engloba, como vimos, a questão da divisão sexual do trabalho e das relações sociais de sexo) passa a ser uma exigência epistemológica.

Percebemos que os estudos que con templam um olhar de gênero forn ecem elementos que evidenciam a necessidade de criação de outros conceitos e métodos de pesquisa. Seja devido a problemáticas que extrapolam as noções disponíveis, seja pelas descon tinuid ades nos espaços de trabalho que implicam uma sucessão de situações e exposições de difícil identificação. Seja também pela importância dos aspectos subj etivos, uma vez que esses estão presentes tanto na definição dos problemas a serem pesquisados, quanto na escolha dos indicadores de análise. Assim, alguns autores, como Ara ú jo e colaboradores (2003), alertam para possíveis inadequações do uso de indicadores construídos para avaliar os efei tos do trabalho na saúde dos homens em estu dos en tre as mulheres. Vale assinalar, porém, que para evitar a permanência numa pers pectiva que não se diferencie significativamente do modelo tradicional de análise da relação saúde-trabalho (da Medicina do Trabalho ou da Sa ú de Ocupaciomal) devemos estar especialmente atentos às formas que os homens e as mulh eres lutam con tra os efei tos patogên icos do ambi en te de trabalho. Nesse senti do cabe lembrar que, conforme Dejours (1995), a saúde é sempre intersubjetiva e social e que a dinâmica exis ten te no interi or dos coletivos de trabalho - sem pre sexuados - tem um papel primordial na sua construção. Ainda de acordo com Dejours (2004), o trabalho apres enta um caráter paradoxal, pois faz a mediação das rel ações de dominação dos homens sobre as mulheres, mas é também o instrumen to decisivo da re a propriação, pelas mulh eres, de seus direitos civis e cívicos, o que representa para nós um meio de con quista da saúde a partir da criação de novas normas de vida.

\section{Considerações finais}

Apesar de estarmos trazendo aqui materiais e en foques tão diversos, podemos identificar algumas convergências ou interfaces significativas entre eles. A indicação da importância da ex periência dos trabalhadores e trabalhadoras, 
dos saberes informais "não escri to s" (Oddone, Re \& Brianti [1977] 1981), para uma maior compreensão das questões que atravessam o trabalho (entendendo que a saúde é uma dessas questões) é um exemplo de tais interfaces.

En tendemos que as relações de gênero têm também um caráter normativo/prescritivo (nesse sen ti do trata-se de uma imposição do meio), que se apresenta, no entanto de forma naturalizada. As relações de gênero e a divisão sexual do trabalho estão na base de uma prescrição naturalizada do trabalho (Brito, 1999). A abordagem de gênero pode ser articulada às análises com foco na atividade de trabalho, na medida em que esta com porta um recon hecim en to das prescrições e das tentativas de subvertê-las. Além disso, o pon to de vista da ativid ade pode certamente ajudar na vis ibilização e com preensão do trabalho concreto das mulheres.

Os en foques aqui recuperados (o trabalho como atividade e como materialidade das relações de gênero) sintonizam com a visão de que a relação saúde - trabalho é complexa e que, por esse motivo, não pode ser apreendida por modelos causais simplificados. Isso porque, seja nos estudos que tratam da atividade de trabalho seja naqueles que discutem as relações de gênero, há indicações de que o trabalho não pode ser vis to exclusivamente como danoso, pois ele tem uma função muito importante também na construção da saúde. Entretanto, mesmo se detivermos o olhar no trabalho como fon te de adoecimento, observamos que uma visão estática do processo de trabalho (onde a dinâmica das mudanças e renormatizações permanentemente em curso e as diferentes relações sociais são ignoradas ou descon si deradas) não é suficiente (e neste sentido a mais pertinente) para que se avance na produção de conhecimen tos sobre a temática, poi s o que se pretende afinal é afirmar as possibilidades de saúde e vida. Essa visão do trabalho que se limita ao trabalho abstrato e assexuado - acaba assemelhando-se à visão das correntes com as quais se preten de diferenciar ao con stituir o campo da Sa ú de do Trabalhador. No que tange ao trabalho como operador de saúde, esse aspecto pertin en te ao trabalho con creto precisa ser mais bem con templado pela Saú de Coletiva. Nas palavras de Teiger (1993), o trabalho é um "con cei to encarnado" ( em um espaço, em um tempo, em um corpo). Assim, para o campo da Saúde do Trabalhador coloca-se o desafio de explorar, mais e melh or, esse aspecto da relação saúde-trabalho, enfim, de detectar as possibilidades, as saídas, as alternativas existen tes ou a serem engendradas para que a vida no trabalho seja mais favor á vel à saúde, ao prazer. Mesmo que já existam alguns esforços nesse sen ti do, é nece s sá rio que se multipliqu em os estu dos que mostrem pistas sobre essas possibilidades. Para tal empreitada, devemos lembrar da importância da interdisciplinarid ade e do diálogo sinérgi co en tre os diferen tes saberes. Reforçar essa pers pectiva torna-se fundamental para que novos con cei tos e métodos sejam esboçados, rompendo efetivamente com uma ótica cen trada exclusiva men te nas formas de adoecimen to, nos aspectos danosos do trabalho e na visão estática de trabalho (de um processo de trabalho pacificado por uma servidão voluntária ao processo de valorização de capital, um meio de trabalho sem variabilidades, trabalhadores passivos aos "impactos"). Cabe lembrar o que alguns estudos já mostraram: não basta reunir profissionais de diferentes formações em um Serviço de Saúde para que uma abord a gem com caráter interdisciplinar (e intersaberes) se desenvolva (Oliveira, 2001). É por isso que acreditamos que as disciplinas e abord a gens aqui brevem en te apre sentadas podem con tri buir para o de s envolvim ento do campo da Saúde do Trabalhador (e da área da Saúde Coletiva). Do mesmo modo, para que a ex periência dos trabalhadbres e trabalhadoras seja efetivam en te incorporada, certamente não basta uma participação periférica desses protagonistas nas pesquisas e ações do campo. Essas questões nos remetem, por um lado, à atuação dos profissionais de Saúde do Trabalhador e, por outro, aos espaços e modos de interação entre coletivos de profissionais de saúde e de coletivos de trabalhadores.

Como consideramos que o trabalho é central para a vida (saúde / doença) e como ac reditamos, conforme Canguilhem (1990), que a saúde é a capacidade de criar novas normas em polaridade dinâmica com o meio (inclusive o meio de trabalho), pensamos que a atuação profissional em Saúde poderia se voltar um pouco mais para a des coberta das possibilidades de mudanças. Isso implicaria a ampliação do diálogo com os diferen tes grupos de trabalhadores, de modo a que as soluções sejam encontradas conjuntamente. Por outro lado, o princípio de "não delegação" proposto pelo Modelo Operário Italiano (Oddone, Re \& Brianti, [1977] 1981) poderia ser mais e mais bem dinamizado, uma vez que a experiência acumulada pelos hom ens e mulheres na ativi- 
dade de trabalho é insubstituível. É nesse sen tido que nos referimos aos espaços e modos de in teração entre profissionais de saúde e trabalhadores. Na medida em que os desafios com os quais nos deparamos são muitos e diversificados, parece-nos ser imprescindível a criação de uma multiplicidade de formas de intervenção com foco na saúde dos trabalhadores e trabalhadoras. Apostamos na invenção de espaços diversificados de debates e análises sobre as relações entre trabalho e saúde, privilegiando-se a ex periência dos pro $t$ a gonistas do trabalho em foco. Esses espaços podem ser pensados como instrumentos de formação, análise e intervenção sobre as questões que intervêm na relação saúde - trabalho. Somen te desta forma poderemos ampliar a com preensão sobre essa relação, a brindo caminho para os diferen tes pon tos de vista e percepções. Por exemplo, através de dispositivos similares às Comunidades Científicas Ampliadas consti tuídas pelo movimento italiano - que em nossas inve stigações temos preferido chamar de Comunidades Ampliadas de
Pesquisa, den tre outros fatores a fim de evitar a su prem acia do saber cien tífico em relação a saberes advindos da prática (Brito, Athayde \& Neves, 2003a), ou de sua outra face, uma visão empobrecida da ciência. Dito de outro modo, com esse processo poderemos não apenas en riquecer as análises, como desenvo lver ações que con templem as singularidades, conforme a proposta aqui apresentada de criação de normas de saúde a partir das situações reais (sempre sexuadas) do trabalho.

Para finalizar, vale ressaltar que provavelmente tenhamos atualmente várias formas de compreender o próprio campo da Saúde do Trabalhador, ou mesmo várias linhas de pensamen to e ação constituídas no seu interior. $\mathrm{O}$ estímulo às iniciativas diferenciadas, que estejam dirigidas à expansão da vida e da saúde dos/as trabalhadores/as, assim como a incorporação de idéias não hegemônicas, devem ser garantidos como estrat é gia de crescimen to, renovação e consolidação do campo e como um fator que favorece a inclusão de mais parceiros.

\section{Referências bibliográficas}

App ay B \& Thébaud-MonyA 2000. Précarisation sociale, pp. 156-161. In H Hirata, F Laborie, H Le Doaré \& D Sen o ti er (orgs.). Dictio nna ire Critique du Féminisme. Presse Universitaire de France, Paris.

Araújo T, Aquino E, Menezes G, Santos C \& Aguiar L 2003. As pectos psico s s ociais do trabalho e distúrbios psíquicos entre trabalhadoras de en fermagem. Rev. Saúde Pública 37(4):424-433.

Brito J 1999. Saúde, trabalho e modos sexuados de viver. Fiocruz, Rio de Janeiro.

Bri to J, At h ayde M \& Neves M (or gs.) 2003. Programa de Formação em Saúde, Gênero e Trabalho nas Escolas. $\mathrm{UFPb}$ /Editora Un iversitária, João Pessoa. ( Caderno de Textos).

Brito J, Athayde M \& Neves (orgs) 2003a. Programa de Formação em Saúde, Gênero e Trabalho nas Escolas. $\mathrm{UFPb}$ /Editora Un iversitária, João Pessoa. ( Caderno de Método e Procedimentos).

Bri to J 2004. Saúde do trabalhador: reflexões a partir da abordagem ergológica, pp. 91-114. In M Figueiredo, M Ath ayde, J Brito \& D Alva rez (orgs). Labiri ntos do tra balho: interro gações e ol ha res sob re o tra balho vivo. DP\&A Editora (Espaços do Desenvolvimento), Rio de Janeiro.

Canguilhem G [1947] 2001 Meios e normas do homem no trabalho. Pro-posições 12(2-3):109-121
Canguilh emG1990. O normal e o pa tológico. 3a ed. revi s ada e aument ad a. Forense Universitária, Rio de Janeiro.

Canguilhem G 2002. La santé: con cept vulgaire et question philosophique, pp. 49-68. In G Canguilhem, Collection Champ Freudien. Georges Canguilhem: Écrits sur la médecine. Éditions du Seuil, Paris.

Caponi S 2003. A saúde como abertura ao risco, pp. 5578. In D Czeresnia \& C Freitas (orgs). Promoção da saúde: conceitos, reflexões, tendências. Fiocruz, Rio de Janeiro.

Clot Y 1981. Une autre regard sur les usines, pp. 251-258. In I Oddone, A Re \& G Brianti. Rédecouvrir l'Éxpérience Ouvrière. Éditions Sociales, Paris.

Clot Y 2001. Clinique du travail, clinique du réel. Les Journal des Psychologues 185:48-51.

Costa S C 2002. Pro teção social, ma ternid adetransferida e lutas pela saúde reprodutiva. Revista Es tudos Fem inistas 10 (2o semestre):301-322.

Czeresnia D 2003. O conceito de saúde e a diferença entre prevenção e promoção, pp. 39-54. In D Czeresnia \& C Freitas (orgs.). Promoção da saúde: conceitos, reflexões, tendências. Fiocruz, Rio de Janeiro.

Daune-Richard A 2003. Qualificações e representações sociais, pp. 65-76. In Hirata \& Maruani (orgs.). As novas fron tei ras da desigualdade: homens e mulheres no mercado de trabalho. Editora Senac, São Paulo. 
D avezies P 1993. Eléments de psychodyna mique du travail. Education Permanente 116:33-46.

Dejours C 1986. Por um novo conceito de saúde. Rev Bras de S Ocupacional 14(54):7-11.

Dejours C 1987. A loucura do trabalho. Cortez, São Paulo.

Dejours C 1995. Comment formuler une problématique de la santé en ergonomie et en médicine du travail? Le Travail Humain 58:1-16.

Dejours C 2004. O Trabalho como enigma, pp. 127-140. In S Lancman \& L Sznelwar (orgs). Christophe Dejou rs: da psicopa tologia à psicodinâmica do trabalho. Fiocruz, Rio de Janeiro; Paralelo 15, Brasília.

Doray B 1981. Le taylo risme: une folie rationnelle? Dunod, Paris.

Doyal L 1994. Ri e sgos para la salud en el entorno doméstico: um marco conceitual. Quadern CAPS 21:25-33.

Guérin F, Lavi lle A, Daniellou F, Duraffourg J, Kergu elenA 2001. Compreender o trabalho pa ra transformá-lo: a prática da ergonomia. Edgard Blüch er Ltda, São Paulo.

Haicault M 1984. La gesti on ordinairede la vie en deux. Sociologie du Travail 3:268-277.

Haraw ay D 1988. Situated knowl eges: The scien ce question in feminism and privil ege of partial pers pective. Feminists Studies 14(3):575-599.

Hirata H \& Zarifian P 2000. Travail (le con cept de), pp. 230-235. In H Hirata, F Laborie, H Le Doré, D Senotier (orgs). Di ctionnaire Critique du Féminisme. PUF, Paris.

Hirata H 2000. Globalização, trabalho e gênero, pp. 21-34. In A Jerusalinskyetal. O valor simbólico do trabalho e o sujeito contemporâneo. Artes e Ofícios, Porto Alegre.

Hi rata H 2002. Divisão sexual do trabalho: o estado das artes, pp. 273-289. In H Hi rata, Nova divisão sexual do tra balho? Um olhar voltado pa ra a em presa e a sociedade. Boitempo Editorial, São Paulo. (Coleção Mundo do Trabalho).

Kergoat D 2000. Division sexuelle du travail et rapports sociaux de sexe, pp. 35-44. In H Hi rata, F Laborie, $\mathrm{H}$ Le Doré, D Senotier (orgs). Dictionn a ire Critique du Féminisme. PUF, Paris.

Laurell A C \& Noriega M 1989. Processo de produção e saúde. Hucitec, São Paulo.

Le Blanc G 2002. La vie humaine: anthropol o gie et bi ol ogie chez Georges Canguilhem. PUF, Paris.
Ma rcondes W, Ro ten berg L, Portela L \& Moreno C 2003 O peso do trabalho "leve" feminino à saúde. São Paulo Perspectiva 17(2):91-101.

Nou roudine A 2003. Risco e atividades humanas: acerc a dapossível positividade aí presente, pp. 37-62. In M Figueiredo, M At h ayde, J Bri to \& D Alvarez (orgs.). Labiri ntos do tra balho: interrogações eol h a ressob reo trabalho vivo. DP\&A Eds, Rio de Janeiro.

Oddone I, Re A \& Brianti G. [1977] 1981). Rédecouvrir l'Éxpérience Ouvrière. Éditions Sociales, Paris.

Oliveira $\mathrm{R}$ 2001. A abordagem das lesões por esforços repetitivos no Centro de Referência em Saúde do Trabalhador do Espírito Santo. Dissertação de mestrado. Escola Naci onal de Sa ú de Públ ica, Fundação Oswaldo Cru z, Rio de Janeiro.

Rifkin J 1995. O fim dos empregos. O declínio inevitável dos ni veis de em prego e a redução da força gl obal de tra batho. Makron Books, São Paulo.

Rocha L, Debert - Ri bei ro M2001. Trabalho, saú dee gênero: estudo compara tivo sobre analistas de sistemas. Revista de Saúde Pública 35(6):539-547.

Schwartz Y 1988. Expérience et connaissance du travail. Éd. Sociales, Paris.

Schwartz Y 2000. Le paradigme ergologique ou un métier de Philosophe. Octarès, Toulouse.

Ta mbellini A M 1976. Contribuição à análise epidemiológica dos acidentes de trânsito. Tese de doutorado. Unicamp, Campinas.

Tah on M.-B 2004. Sociologie de rapports de sexe. Collecti on "Le sens Sscial". Rennes/Ottawa: Presses Univers itaires de Rennes/ Les Presses de l'Un iversité d'Ott awa.

Terssac G \& Ma ggi B. 2004. O trabalho e a abord a gem ergonômica, pp 79-104. In Daniellou (org). A ergonomia em bu sca de seus princípios: deba tes epistemológicos. Editora Edgard Blücher, São Paulo.

Teiger C 1993. L'a pproche ergonomique: du travail humain à l'activité des hommes et des femmes au travail. Education Permanente 116:71-96.

Vogel L 2001. La dimensión de género en salud laboral Primeras conclusiones de uma encuesta eu ropea. Dispon ível em www.etuc.org/tutb/fr/femmes. Acessado em setembro de 2001.

Wisner A 1994. A inteligência no trabalho: textos selecionados de ergonomia. Fundacentro, São Paulo.

Artigo apre sent ado em 15/06/2005

Aprovado em 27/07/2005

Versão final apre sent ada em 27/07/2005 